\title{
Effect of Electrical Current Applied in Soaking Conditions on Germination of Acacia and Maize Seeds
}

\author{
O. Gätjens-Boniche ${ }^{1}$, C. Díaz ${ }^{2,3}$, L. Hernández-Vásquez ${ }^{1}$, \\ P. Chavarría-Rodríguez ${ }^{1}$ and E. Martínez-Ávila ${ }^{1}$ \\ ${ }_{1}^{1}$ Laboratorio de Biología Molecular, Escuela de Ciencias Naturales y Exactas, Instituto Tecnológico de Costa \\ Rica, Santa Clara, San Carlos, Alajuela, Costa Rica. \\ ${ }^{2}$ Instituto Clodomiro Picado, Facultad de Microbiología, Universidad de Costa Rica, San José, Costa Rica. \\ ${ }^{3}$ Departamento de Bioquímica, Escuela de Medicina, Universidad de Costa Rica, San José, Costa Rica.
}

\begin{abstract}
Plant germination is a process required for plant survival, which responds to different environmental signals. This investigation was designed to develop a methodology to improve the germination process of two different plants, maize fast germination seeds and acacia slow-germinating seeds with dormancy, by the application of direct electrical current. Discharge treatments of seeds submerged in a phosphate-buffer solution $I X(P B S I X), p H: 7.0$, varied in terms of intervals between discharges and exposure voltages. Heating the Acacia mangium seeds in boiling water before the application of discharges, highly increased germination capacity $(G C)$ in all the treatments, showing the best effect by applying $10 \mathrm{~V}$ every $15 \mathrm{~min}(76.4 \%$ compared to $50 \%$ of the control). Plants length also significantly increased about $0.87 \mathrm{~cm}$ at four weeks compared to the control ( $p<0.05)$, obtaining the best results when $20 \mathrm{~V}$ and $40 \mathrm{~V}$ discharges were applied every 15 and 5 min, respectively. In the case of maize seeds, when strength of growing was determined measuring the length of the radicles, the best effect was observed applying $10 \mathrm{~V}$ every 5 and $30 \mathrm{~min}(p<0.05)$, same treatments that increased the germination capacity in maize to 90-100\%. At day 15, ten treatments showed statistically significant differences increasing growth in maize plants $(p<0.05)$ compared to the control, with the best effect observed when $20 \mathrm{~V}$ discharges were applied every $30 \mathrm{~min}(34.9 \mathrm{~cm}$ compared to $27.4 \mathrm{~cm}$ of the control). Several electrical schemes improved germination and growth in both types of seeds but a clear treatmentresponse relationship could not be made, neither for interval time nor for applied voltage.
\end{abstract}

Keywords: growth, electrical discharges, dormancy, maize seeds, acacia seeds.

\section{Introduction}

Germination, the resumption of the growth of the seed embryo after a period of dormancy, does not take place unless the seed has been placed into a favorable environment. The primary conditions to fulfill that are adequate water and oxygen supplies and a suitable temperature. During germination water diffuses through the seed coats into the latent embryo, which has been almost completely dried during the period of dormancy, causing swelling of the seed and often, rupturing the coat (Taiz and Zeiger, 2006).

Acacia mangium is a tree native from Australia, New Guinea and east Indonesia (Simmons, 1987), and it is the most commercially important and widely planted tropical acacia in the world (Krisnawati, et al., 2011). It grows in Central America, where its wood is widely used in construction. The main problem for reforestation programs using Acacia trees are poor seed germination due to physical dormancy caused by the waterimpermeable seed coat (Walters et al., 2004; Holmes et al., 1987). On the other hand, maize (Zea mays) is a perennial plant, native from the American continent, which grows around the world as one of the main grains for human feeding together with rice and wheat (Ranum et al., 2014). Improving the germination process and early seedling growth is an important constraint for global production of these crops (Guan et al., 2009).

It has been reported that Acacia mangium seeds have dormancy, whereby they need a pre-germination period to activate and promote germination. Various artificial techniques have been used to successfully overcome physical dormancy in legumes such as acacia species. Some studies have shown that the highest germination percentages are obtained when seeds are submerged in boiling water before being planted (Walters et al., 2004; Rasebeka et al., 2014; Pound et al., 2014). Another practice that has been applied with good results in some crops (including maize) to increase germination is soaking the seeds for 10-25h in water, (Harris et al., 1999). Physical dormancy is the water impermeability of seed coats and it has been suggested that variations in the seed coat structure among neotropical Acacia species could be related to different regenerative responses to environmental conditions (Venier et al., 2014). Overall, information on seed dormancy of arid zone species is limited and particularly based on Oceania's arid zone (Pound et al., 2014).

There are just few studies that report the effect of electric fields in plant germination. Some of them reported an increase in germination and other growth parameters, but also showed a decrease and even affectation on the same parameters when direct electric shocks were applied to seeds through different

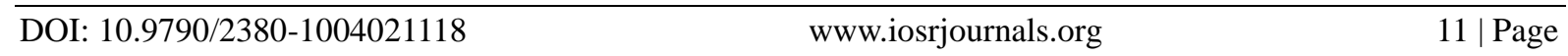


conduction mechanisms and various combinations of voltage and time (Zhang and Hashinaga, 1997; Moon and Chung, 2000; Kobayashi et al., 2004; Lynikiene et al., 2006; Nikpeyma et al., 2011; Yi et al., 2012; Gandhare and Patwardhan, 2014).

In this study, we investigated the effect of electrical discharges (under soaking conditions) on two different types of seeds: fast germination seed of maize and slow-germinating seeds with dormancy of acacia, looking for a protocol to improve the process of germination in these plants and their potential growth.

\section{Materials and Methods}

\section{Treatment of seeds}

In each experiment, a sample of 50 seeds was treated with different schemes of electric discharges, which varied in voltage and frequency, with a constant time of exposure of $25 \mathrm{sec}$ each. Time interval and the elapded time of electrical discharges were applied and controlled by a power supply with a stable output of direct current (DC), which was designed and assembled specifically for this study (Fig 1).

In both species, two different parameters were determined after application of electrical discharges: germination capacity and growth strength, the latter being measured by the length of the plants stem. In the case of maize, root length was also measured.

Table 1 shows the different schemes of electrical treatment that were applied on these seeds.

Table 1. Electrical schemes applied to acacia and maize seeds.

\begin{tabular}{|c|c|c|}
\hline Treatment & Voltage & Time Interval \\
\hline Control & $0 \mathrm{v}$ & $0 \mathrm{~min}$ \\
\hline 1 & $10 \mathrm{v}$ & $5 \mathrm{~min}$ \\
\hline 2 & $20 \mathrm{v}$ & $5 \mathrm{~min}$ \\
\hline 3 & $40 \mathrm{v}$ & $5 \mathrm{~min}$ \\
\hline 4 & $70 \mathrm{v}$ & $5 \mathrm{~min}$ \\
\hline 5 & $10 \mathrm{v}$ & $15 \mathrm{~min}$ \\
\hline 6 & $20 \mathrm{v}$ & $15 \mathrm{~min}$ \\
\hline 7 & $40 \mathrm{v}$ & $15 \mathrm{~min}$ \\
\hline 8 & $70 \mathrm{r}$ & $15 \mathrm{~min}$ \\
\hline 9 & $10 \mathrm{v}$ & $30 \mathrm{~min}$ \\
\hline 10 & $20 \mathrm{v}$ & $30 \mathrm{~min}$ \\
\hline 11 & $40 \mathrm{v}$ & $30 \mathrm{~min}$ \\
\hline 12 & $70 \mathrm{v}$ & $30 \mathrm{~min}$ \\
\hline
\end{tabular}

\section{Experiments with Acacia mangium seeds}

Acacia mangium seeds were supplied by the Forest Seed Laboratory of Technological Institute of Costa Rica and were collected from natural field trees in the month of March. In the first set of experiments, half of the treatments were carried out by heating the seeds for a period of $2 \mathrm{~min}$, previously submerging them in boiling water. A second experiment was performed, in the absence of heating conditions, under the same voltage and interval discharges. Electric discharges were applied while the seeds were submerged in a phosphate buffer solution 1X (PBS 1X, $10 \mathrm{mM} \mathrm{PO}_{4}{ }^{3-}, 137 \mathrm{mM} \mathrm{NaCl}$ and $2.7 \mathrm{mM} \mathrm{KCl}$, with a $\mathrm{pH}$ of 7.0 , prepared in sterile distilled/deionized water) within a copper basket inside an electrophoresis chamber. The seeds remained in solution during 24 hours (the total time that the experiment lasted) and at specific intervals of time, predefined voltage electric discharges, were applied, which lasted 25 seconds each. The germination capacity (GC) was determined at day 14 by counting the total hit of seeds in each experimental treatment which present at least radicles, in culture conditions that allowed germination and growth. Germination capacity (GC) shows the percentage of seeds that germinate at the end of the test (Edwards and El-Kassaby, 1996). All seeds were washed with sterile distilled water and put into petri dishes during five days along with two wetted layers of filter paper (Whatman No. 1) in distilled water. Then, seedlings were placed on trays containing the same soil land, allowing them to grow during 30 days in a greenhouse under environmental conditions $\left(23.8^{\circ} \mathrm{C}\right.$ and relative humidity of $82.75 \%$ ).

Measuring the stem length of acacia plants was performed at 2 and 4 weeks. 


\section{Experiments with Zea mays seeds}

The same procedure applied to acacia seeds, was used to treat maize seeds, with the difference that no treatment in boiling water was applied to these seeds. Schemes of electrical discharges are presented in Table 1. Commercial maize seeds (variety Diamantes 8843) were used for the experiments.

Germinating seeds were first placed into petri dishes during 5 days and the germination capacity (GC) was determined during this period of time. The total germination capacity (percentage of seeds that germinate at day 5) was determined counting the number of plants that present at least radicles. Then, seedlings were placed on trays, allowing them to grow in a greenhouse under environmental conditions $\left(23.8^{\circ} \mathrm{C}\right.$ and relative humidity of $82.75 \%$ ). Measuring the root length of maize seedlings was performed at day 5 and stem length was measured at 5,10 , and 15 days of culture.

\section{Statistical Analysis}

To determine the effect of discharges at different voltages and time intervals on stem and root growth, a randomized factorial $2^{2}$ design was performed. Data was statistically analyzed by ANOVA followed by Duncan's multiple interval test using SPSS statistical program version 10.0. In addition, Student's two-tailed $t$ test was used. All experiments were repeated three times, but the data was taken from the last experiments.

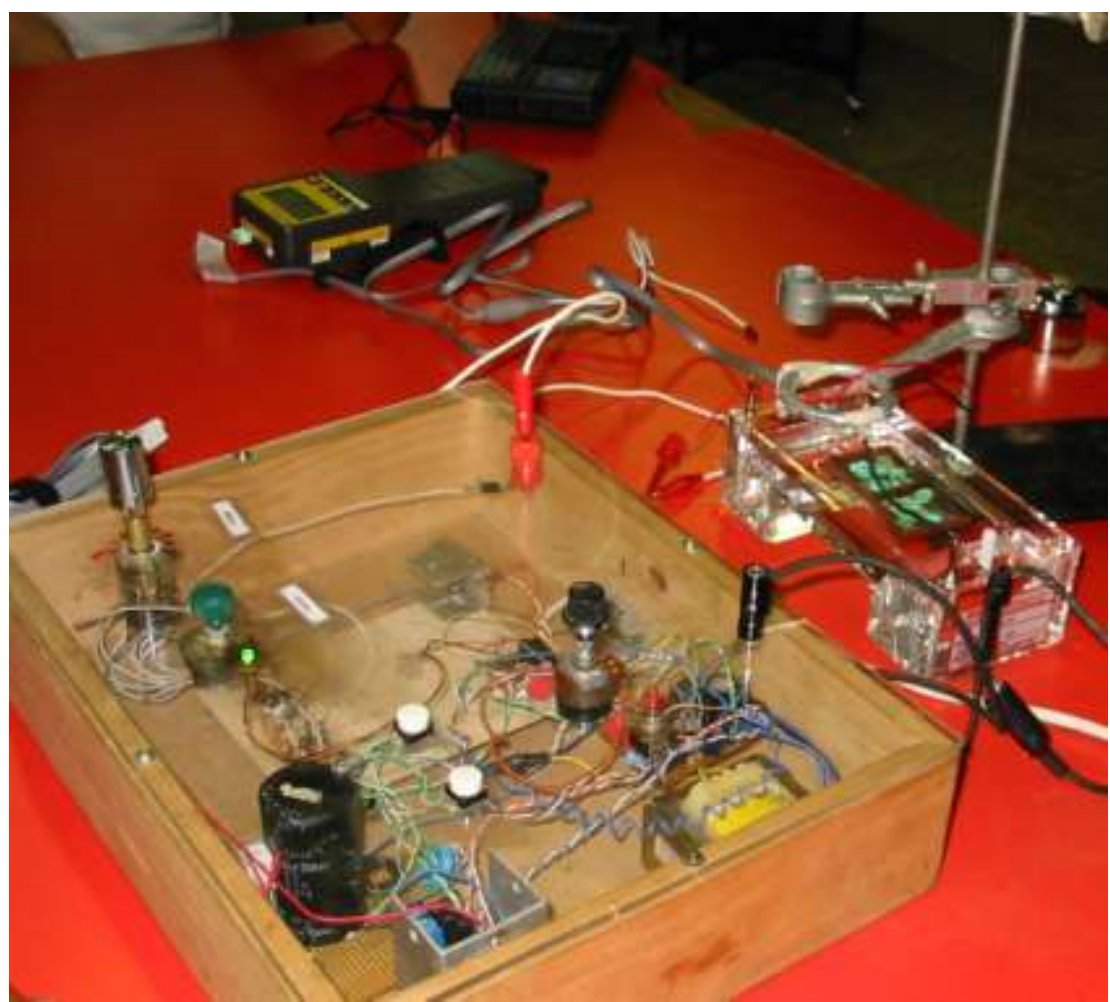

Figure 1. Device designed and assembled specifically for this study to control intervals and the elapded time as well as the electrical discharges (direct current) applied to seeds.

\section{Results}

\section{Determination of Acacia mangium seeds germination after treatment with electric discharges}

As we observed in Fig 2A, in acacia seeds, several schemes of treatment increase the germination capacity (GC) at some extent, measured at day 14. The best effect was observed in seeds treated with $70 \mathrm{~V}$ applied every $15 \mathrm{~min}$, with a percentage of $16.3 \%$, increasing approximately eight times the results presented by the control. However, with the exception of $10 \mathrm{~V}$ discharges, 30 minutes of treatment seems to completely inhibit germination in Acacia.

When a heating treatment (in boiling water) was applied before the electrical discharges (Fig 2B) we observed an increase in germination rates in all the treatments, including the control, which started around $50 \%$ higher than the percentage observed in seeds without heating (Fig 2A). The scheme of the treatment with the highest germination capacity was $10 \mathrm{~V}$ every $15 \mathrm{~min}$, which showed a value of $76.4 \%$ of the total of seeds. An increase in voltage with the same interval of time $(20 \mathrm{~V}, 15 \mathrm{~min})$ gave the lowest germination percentage (germination capacity), corresponding to $43 \%$, lower even than the control. 

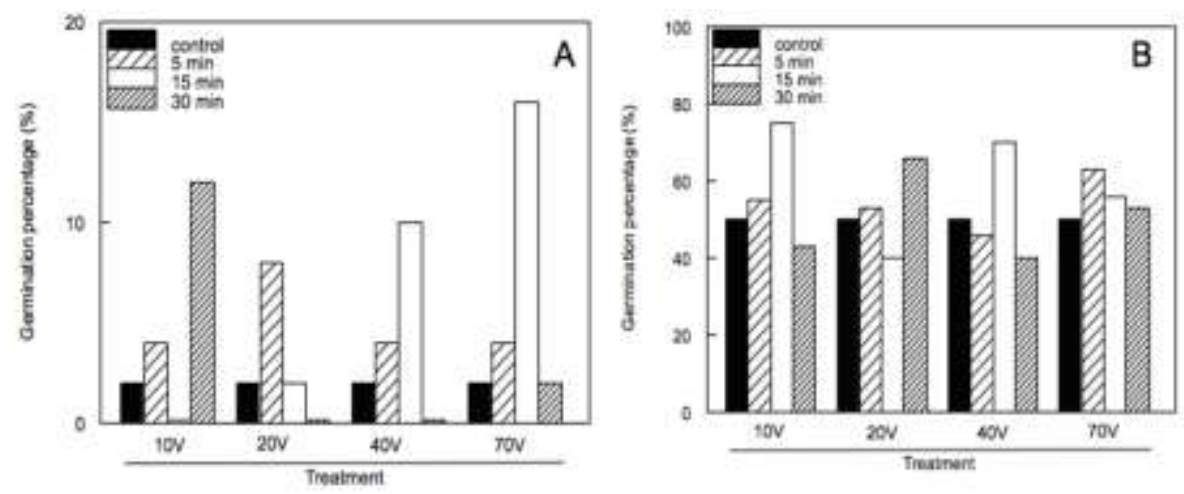

Figure 2. Germination capacity (GC) of Acacia mangium seeds after application of electrical discharges.

Evaluation was performed 14 days after planting. A: without pre-treatment in boiling water; B: with pretreatment in boiling water for $2 \mathrm{~min}$. Germination capacity expressed as the percentage of seeds that germinate at day 14.

\section{Determination of stem length of Acacia mangium plants}

At two weeks, when stems were measured, four schemes of treatment showed an improvement in growth compared to controls (Fig 3C). These schemes were $20 \mathrm{~V}$, every 5 and 15 min (mean $=4.09 \mathrm{~cm}$ and mean $=4.49 \mathrm{~cm}$ respectively), $40 \mathrm{~V}$ every $5 \mathrm{~min}(\mathrm{mean}=4.34 \mathrm{~cm})$, and $70 \mathrm{~V}$ every $30 \mathrm{~min}(\mathrm{mean}=4.04 \mathrm{~cm})$ and $3.81 \mathrm{~cm}$ for the control treatment. However, according to Duncan's multiple interval test, a statistically significant difference was found only in the treatment of $20 \mathrm{~V}$ every 15 minutes $(\mathrm{p}<0.05)$.

Determination of acacia growth, performed at week 4 (Fig 3C), showed that schemes of treatment of $20 \mathrm{~V}$ every $15 \mathrm{~min}$ and $40 \mathrm{~V}$ every $5 \mathrm{~min}$, had the best improvement (mean $=5.02 \mathrm{~cm}$ and mean $=5.35$, compared to the control, mean $=4.48 \mathrm{~cm}$ ). Both treatments showed a statistically significant difference according to Duncan's multiple interval test, confirmed also by Student t-test $(\mathrm{p}<0.05)$.
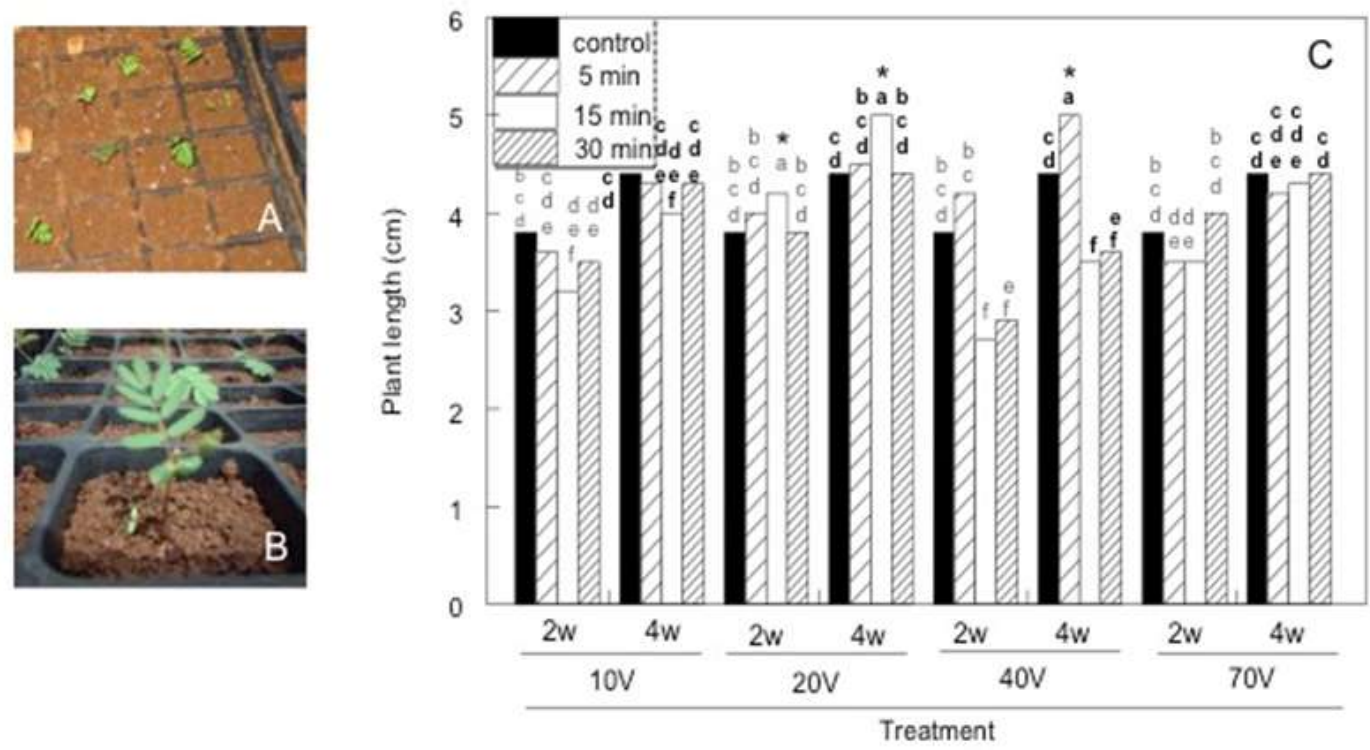

Figure 3. Measurement of stem length of Acacia mangium plants after application of electrical discharge treatments. A, B: Acacia plants. C: Measurement of acacia stem length at 2 and 4 weeks $(2 \mathrm{w}$ and $4 \mathrm{w}$ respectively). Different letters represent statistically significant differences within a column group for each evaluation day according to Duncan's multiple interval test with a $\mathrm{p}<0.05$. The asterisks indicate significant differences compared to controls.

\section{Determination of maize seed germination after treatment with electrical discharges}

Fig 4A shows that several schemes of treatment improve the germination capacity of these seeds. The best result was obtained with $10 \mathrm{~V}$ every $30 \mathrm{~min}$, with a $98 \%$ turnout, compared to the control value of $61 \%$ of seeds. In the case of maize seeds, germination was not determined after 5 days due to the fact that high percentage of the effect was reached during this period. 


\section{Determination of root and stem length of maize plants}

When we determined the length of the radicles of maize plants at day 5 , it was observed that the schemes of $10 \mathrm{~V}$ every 5 and $30 \mathrm{~min}$ showed the statistically significant higher improvement $(\mathrm{p}<0.05)$, being the latter the better effect (Fig 4B). Average length of the roots in the control plants was $3.1 \mathrm{~cm}$ whereas after the experimental scheme of $10 \mathrm{~V}$ every $30 \mathrm{~min}$, the average length was $5.22 \mathrm{~cm}$.
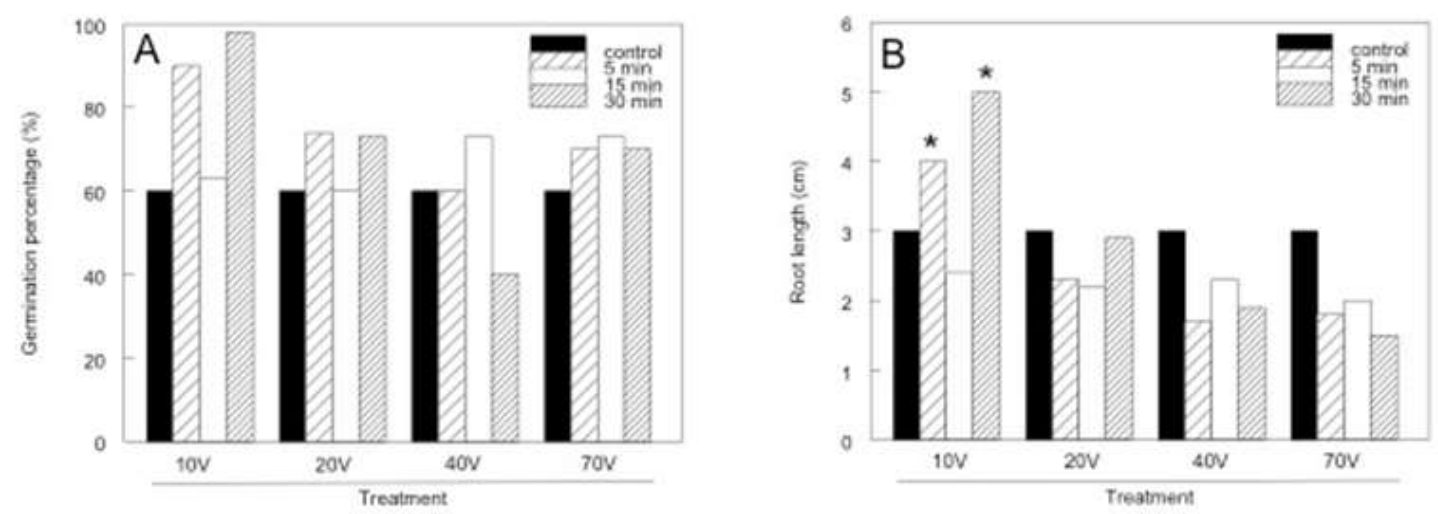

Figure 4. Germination capacity (GC) and root length of maize seeds at day 5 after application of electrical discharges. A: Germination capacity expressed as the percentage of seeds that germinate at day 5. B: Average roots length. The asterisks indicate significant differences compared to controls, according to Duncan's multiple interval test with a $\mathrm{p}<0.05$.

Five days after growing in petri dishes (Fig 5A), maize seeds were transferred to soil (Fig 5B). Fig 5C shows the size of the plants at days 5, 10 and 15. We observed that on day 5, the best results were obtained with 20 and $40 \mathrm{~V}$ every $5 \mathrm{~min}$ with a $\mathrm{p}<0.05$. At day 10 , the best improvement was obtained at $20 \mathrm{~V}$ every 5 and 30 $\mathrm{min}$ and $40 \mathrm{~V}$ every $5 \mathrm{~min}(\mathrm{p}<0.05)$. At day 15 , ten treatments showed statistically significant higher growth in maize plants $(\mathrm{p}<0.05) ; 20 \mathrm{~V}$ every $30 \mathrm{~min}$ gave the best results $(34.9 \mathrm{~cm}$ compared with $27.4 \mathrm{~cm}$ to the control treatment).
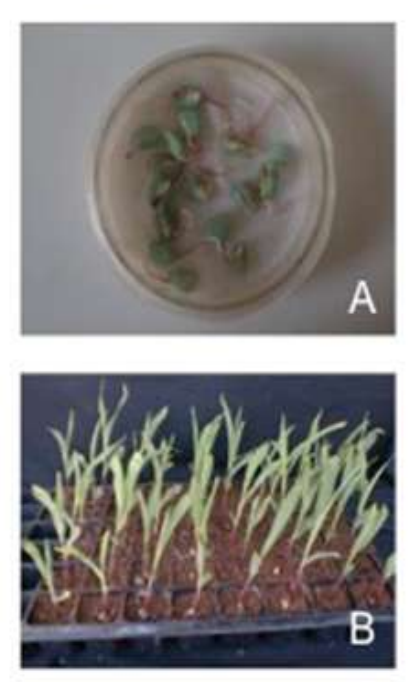

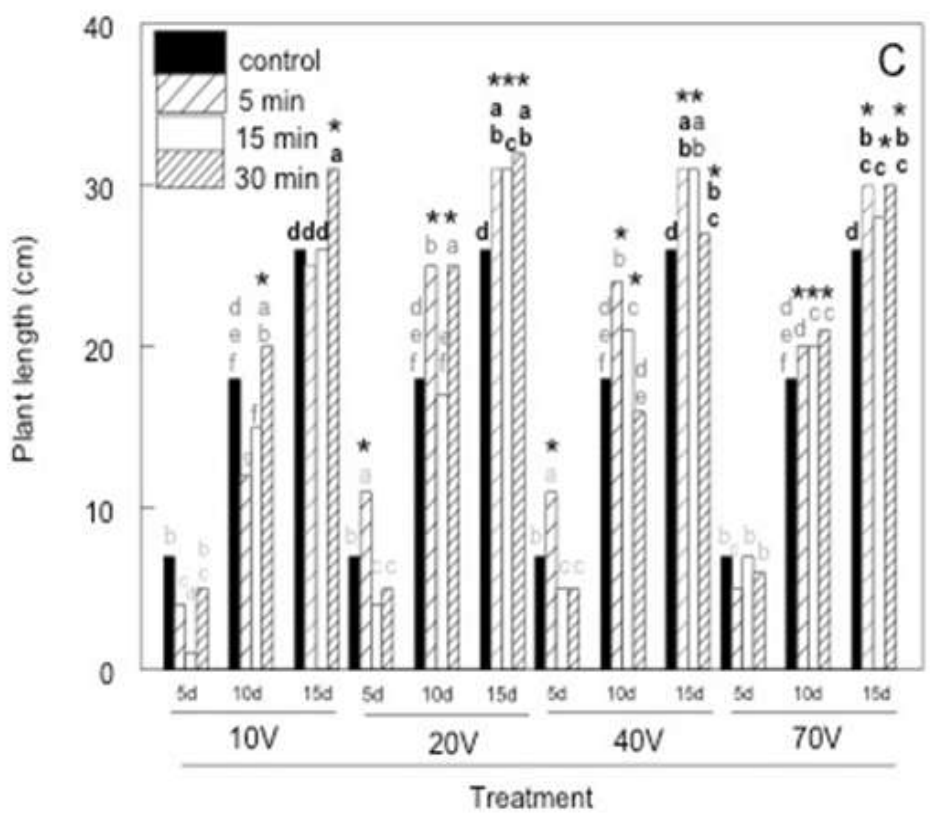

Figure 5. Measurement of stem length of maize plants treated with electrical discharges after 15 days of growing. A, B: Maize plants. C: Measurement of maize stem length. Different letters represent statistically significant differences within a column group for each evaluation day, according to Duncan's multiple interval test with a $\mathrm{p}<0.05$. The asterisks indicate significant differences compared to controls. 


\section{Discussion}

Upon analyzing the results, it may be concluded that electric stimulation favors, in general terms, the germination capacity and growth of acacia and maize seeds. A similar effect has been observed in other plant seeds such as morning glory, cotton, tomato, carrot, radish, beet and barley (Isobe et al., 1999; Lynikiene et al., 2006; Gandhare and Patwardhan, 2014; Shi et al., 2014). Although several electrical treatments improved germination capacity and growth in both types of seeds, a clear treatment-response relationship could not be made, neither for time nor for voltage. As we observed also, these studies show that some schemes of electric fields can work inversely, decreasing (or even inhibiting), germination ability of the seeds. For example, in acacia seeds when $10 \mathrm{~V}$ were applied with intervals of 5 and $30 \mathrm{~min}$, both treatments improve germination capacity, being the interval of $30 \mathrm{~min}$ much more effective than the treatment applied every $5 \mathrm{~min}$. On the contrary, the same voltage $(10 \mathrm{~V})$ applied every $15 \mathrm{~min}$ completely abolished the process of germination. In the case of the maximum voltage applied $(70 \mathrm{~V})$, the results were inverse, the best germination capacity was obtained when discharges were applied every $15 \mathrm{~min}$, whereas $70 \mathrm{~V}$ every 30 min gave the same results than the control and 70V every 5 min doubled the germination capacity obtained in the control seeds. The same opposite pattern could also be seen in maize seeds where for example 10 and $40 \mathrm{~V}$ every 30 min gave completely opposite effects, in the first case the germination capacity was almost duplicated, whereas at $40 \mathrm{~V}$ about one third of the seeds were completely inhibited to germinate, respect to the control. But, in spite of these apparent inexplicable results, several schemes of electrical treatment resulted successful and very promising.

An study performed by Isobe et al. (1999) showed that electric discharges applied to dry morning glory seeds can affect water absorption. They explained the effect in terms of changes in electrical polarization of cell membranes and the hydration of stored macromolecules. Moreover, Shi et al. (2014) indicated that high voltage electric field influence transmembrane potential affecting permeability of cell membrane.

Isobe et al. (1999) explained the negative effect of electrical current in terms of water distribution into the seeds. In their case, the treatment of morning glory seeds with electric field for 60 min alters water molecules in the cells, which were more restricted in motion when cells were treated with the discharges. Therefore, treatment with electric fields reduces the mobile water associated with active cells. Another effect they reported was the reorientation and disarrangement of the membrane components of the seeds due to the electric field, which can also be related to water distribution.

So, the application of electric fields could influence the permeability of the cellular membrane and affect seed germination, but it is important to control both the voltage and the time of exposure to obtain the required effects without altering the normal processes to the point where the seeds would result damaged.

Due to the fact that membranes have electrical potentials, which are determined by different concentrations of molecules and ions across them, changes in electrical properties due to discharge applications, can also affect cellular processes.

The variations observed here among several voltages and time intervals between electrical treatments may be due to small differences in the water content and even in the age of the acacia seeds, as they were collected from different trees found in the same field. In addition, the unfavorable variations in the results may be due to an excessive and accelerated hydration of the reserve substances, such as starches, proteins and even, enzymes. This happens when an unusual influx and accumulation of water would result in damage of the membrane systems, causing an irregular organization of the cell structures. Based on this, it could be assumed that the seeds that present a greater degree of dormancy dehydration such as acacia seeds, could be negatively affected with the application of certain electrical treatments, since in this type of seed the influx of water and hydration could be more stressful due to its quiescent physiological state. According to Kindzerskii and Petty (2000), rapid hydration of the seeds could provoke an abnormal and accelerated metabolic state, which could also cause the release of free radicals, especially oxygen radicals, which in turn, could damage by oxidation, some important molecules. Some studies have suggested that seed heating, such as for instance after fire exposure, could enhance germination potential (Auld and O'Connell, 1991). However, in the case of seeds grown in natural conditions, Walters et al. (2004) have shown that burning does not affect germination of several species of acacia.

To test this, we decided to apply heating (boiling water) before electric fields were tested. We obtained a very significant effect with this pretreatment, even in control seeds not exposed to electricity. From an initial $2 \%$ germination capacity observed in control acacia seeds, we switch to a $50 \%$ of germination after dipping the seeds in boiling water for $2 \mathrm{~min}$. We can say that this pre-germination procedure worked even better than the electric field itself, but both treatments together gave the best results.

Priming of the seeds by soaking them for 10-25 h, depending on the crop, has shown good results increasing germination and other processes, giving plants more vigor, with better drought tolerance, earlier flowering, earlier harvest capacity and higher grain yield (Harris et al., 1999).

The considerable benefits that can be achieved from priming have led to speculation that this process may result in a major physiological change that persists throughout growth to influence yield, and some results 
have indicated that priming can result also in resistance to, or avoidance of, disease infections (Rashid et al., 2004). The process of imbibition has been clearly described in maize (McDonald et al., 1994). These authors suggest that water is taken up through two separate pathways, the first resulting in near full embryo hydration within $15 \mathrm{~h}$, and the second resulting in endosperm hydration that can take longer than $48 \mathrm{~h}$. At germination, the moisture content of the embryo is around 50\%, whereas the moisture content of the endosperm is still 25-30\%, and it subsequently keeps getting wet (McDonald et al., 1994).

In our study, we applied the electric current when the seeds were submerged in saline buffer solution PBS 1X, and we allowed the seeds to remain into this solution for $24 \mathrm{~h}$. In this case the observations obtained can be the result of the combination of the electricity and the imbibition process. So we were improving both, the ability of the water to slowly enter the seeds and at the same time, the current applied could favor the entrance of ions changing the properties of cell membranes. Water uptake by the seed generally occurs in three phases: rapid initial uptake, a lag phase with limited further uptake and then a phase of rapid water entrance associated with radicle emergence (Bewley and Black, 1994). Imbibition is identified with the first phase of water uptake and is a physical process, although metabolic activity is initiated as the seeds reach the minimal water potential, before they reach full moisture content. We hypothesized that moderate electrical stimulation under soaking conditions could affect the permeability of plasma membrane and increase the movement of water and ions to the cells, accelerating the germination process and allowing the plants to grow better. We conclude that this experimental procedure could be applied with positive results, not only inducing higher germination of different types of seeds, but also developing better plants, more capable to survive to different environmental conditions.

\section{References}

[1]. Bewley, J.D.; Black, M. 1994. Seeds: Physiology of Development and Germination, $2^{\text {nd }}$ edn. New York, USA: Plenum Press.

[2]. Edwards, D.G.W.; El-Kassaby, Y.A. 1996. The effect of stratification and artificial light on the germination of mountain hemlock seeds. Seed Science and Technology 24: 225-235.

[3]. Gandhare, W.Z.; Patwardhan, M.S. 2014. A New Approach of Electric Field Adoption for Germination Improvement. Journal of Power and Energy Engineering 2: 13-18.

[4]. Guan, Y.; Hu, J.; Wang, X.; Shao Chen, X. 2009. Seed priming with chitosan improves maize germination and seedling growth in relation to physiological changes under low temperature stress. J. Zhejiang Univ. Sci. B 10: 427-433.

[5]. Harris, D.; Joshi, A.; Khan, P.A.; Gothkar, P.; Sodhi, P.S. 1999. On-farm seed priming in semi-arid agriculture: development and evaluation in maize, rice and chickpea in India using participatory methods. Experimental Agriculture 35: 15-29.

[6]. Holmes, R.J.; McDonald, J.; Juritz, J. 1987. Effects of clearing treatment on seed bank of sicpithe Alinene invasive shrubs Acacia saligna and Acacia cyclops in the southern and

[7]. Isobe, S.; Ishida, N.; Koizumi M.; Kano, H.; Hazlewood, C. 1999. Effect of electric field on physical states of cell-associated water in germinating morning glory seeds observed by ${ }^{1}$ H-NMR. Biochimica et Biophysica Acta 1426: 17-31.

[8]. Kindzelskii, A.L; Petty H.R. 2000. Extremely low frequency pulsed DC electric fields promote neutrophil extension, metabolic resonance and DNA damage when phase-matched with metabolic oscillators. Biochimica et Biophysica Acta 1495: 90-111.

[9]. Kobayashi, M.; Soda, N.; Miyo T.; Ueda, Y. 2004. Effects of combined DC and AC magnetic fields on germination of hornwort seeds. Bioelectromagnetics 25: 552-9.

[10]. Krisnawati, H.; Kallio, M.; Kanninen, M. 2011. Acacia mangium Willd.: ecology, silviculture and productivity. CIFOR, Bogor, Indonesia.

[11]. Lynikiene, S.; Pozeliene, A.; Rutkauskas, G. 2006. Influence of corona discharge field on seed viability and dynamics of germination. International Agrophysics 20: 1995-200.

[12]. McDonald, M.B.; Sullivan, J.; Lauer M.J. 1994. The pathway of water uptake in maize seeds. Seed Science and Technology 22: 79-90.

[13]. Moon, J.D.; Chung H.S. 2000. Acceleration of germination of tomato seed by applying AC electric and magnetic fields. Journal of Electrostatics 48: 103-114.

[14]. Nikpeyma, Y.; Turanli, M.; Ak, B.E. 2011. The stimulative effect of shocking by electric current on pistachio (Pistacia vera) seed germination and growth. Acta Hortic 912: 295-299.

[15]. Pound, L.M.; Ainsley, P.J.; Facelli J.M. 2014. Dormancy-breaking and germination requirements for seedsisepiof Acacia papyrocarpa, Acacia oswaldii and Senna artemisioides ssp. x coriacea, three Australian arid-zone Fabaceae species. Australian Journal of Botany 62: 546-557.

[16]. Rasebeka, L.; Mathowa, T.; Mojeremane W. 2014. Effect of Seed Pre-sowing Treatment on Germination of Three Acacia Species Indigenous to Botswana. International Journal of Plant \& Soil Science 3(1): 62-70.

[17]. Rashid, A.; Harris, D.; Hollington, P.; Shamsher A. 2004. On-farm seed priming reduces yield losses of mungbean (Vigna radiata) associated with mungbean yellow mosaic virus in the North West Frontier Province of Pakistan. Crop Protection 23: 111924.

[18]. Shi, M.; Fan, J.; Li, S.; Yu, X.; Liang, X. 2014. The influence of high voltage electric field for barley seed germination and its mechanism. Applied Mechanics and Materials 675-677: 1142-1145.

[19]. Simmons, M.H. 1987. The genus Acacia. p: 7-10. In: M.H. Simmons, ed. Acacias of Australia. Vol. 1, Nelson Publishers, Malbourne, Vic, Australia.

[20]. Taiz, L.; Zeiger E. 2006. Plant Physiology (Fourth Edition). Chapter 23. Sinauer Associates, Inc. Publishers, Sunderland, MA.

[21]. Venier, P.; Funes, W.; Carrizo Garcia C. 2012. Physical dormancy and histological features of seeds of five Acacia species (Fabaceae) from xerophytic forest in central Argentina. Flora 207: 39- 46.

[22]. Walters, M.; Midgley, J.J.; Somers M.J. 2004. Effects of fire and fire intensity on the germination and establishment of Acacia karroo, Acacia nilotica, Acacia luederitzii and Dichrostachys cinerea in the field. BMC Ecology 4: 3-13.

[23]. Yi, J.Y.; Choi, J.W.; Jeon, B.Y.; Jung, L.; Park, D. H. 2012. Effects of a low-voltage electric pulse charged to culture soil on plant growth and variations of the bacterial community. Agricultural Science 3 (3): 339-346.

[24]. Zhang, H.; Hashinaga, F. 1997. Effect of high electric fields on the germination and early growth of some vegetable seed. Journal of the Japanese Society for Horticultural Science 66: 347-52. 
TABLES AND FIGURES.

Table 1. Electrical schemes applied to acacia and maize seeds.

Figure 1. Device designed and assembled specifically for this study to control intervals and the elapded time as well as the electrical discharges (direct current) applied to seeds.

Figure 2. Germination capacity (GC) of Acacia mangium seeds after application of electrical discharges. Evaluation was performed 14 days after planting. A: without pre-treatment in boiling water; B: with pretreatment in boiling water for $2 \mathrm{~min}$. Germination capacity expressed as the percentage of seeds that germinate at day 14.

Figure 3. Measurement of stem length of Acacia mangium plants after application of electrical discharge treatments. A, B: Acacia plants. C: Measurement of acacia stem length at 2 and 4 weeks $(2 \mathrm{w}$ and $4 \mathrm{w}$ respectively). Different letters represent statistically significant differences within a column group for each evaluation day according to Duncan's multiple interval test with a $\mathrm{p}<0.05$. The asterisks indicate significant differences compared to controls.

Figure 4. Germination capacity (GC) and root length of maize seeds at day 5 after application of electrical discharges. A: Germination capacity expressed as the percentage of seeds that germinate at day 5. B: Average roots length. The asterisks indicate significant differences compared to controls, according to Duncan's multiple interval test with a $\mathrm{p}<0.05$.

Figure 5. Measurement of stem length of maize plants treated with electrical discharges after 15 days of growing. A, B: Maize plants. C: Measurement of maize stem length. Different letters represent statistically significant differences within a column group for each evaluation day, according to Duncan's multiple interval test with a $\mathrm{p}<0.05$. The asterisks indicate significant differences compared to controls. 